\title{
ESTRATÉGIAS DE INVESTIMENTOS E INTEGRAÇÃO DE MERCADOS ACIONÁRIOS INTERNACIONAIS: uma análise empírica
}

\author{
Investment strategies and international stock markets integration: \\ an empirical analysis
}

\section{Paulo Sergio Macuchen Nogas ${ }^{[a]}$, Wesley Vieira da Silva ${ }^{[b]}$, Luiz Carlos Duclós ${ }^{[c]}$}

[a] Doutorando em Administração pela Pontifícia Universidade Católica do Paraná (PUCPR), Curitiba, PR - Brasil, e-mail: paulo.nogas@gmail.com

[b] Professor do Doutorado em Administração da Pontifícia Universidade Católica do Paraná (PUCPR), Curitiba, PR, e-mail: wesley.vieira@pucpr.br

[c] Professor do Doutorado em Administração da Pontifícia Universidade Católica do Paraná (PUCPR), Curitiba, PR, e-mail: luiz.duclos@pucpr.br

\section{Resumo}

O presente trabalho tem como objetivo avaliar o grau de integração entre as taxas de rentabilidade dos índices dos principais mercados acionários nos seguintes países: Índia, Brasil, Egito, França, Alemanha, Hong Kong, Indonésia, Israel, Japão, Malásia, Argentina, México, Holanda, Cingapura, Reino Unido e Estados Unidos. Foram utilizados dados, compreendidos no período entre janeiro de 1998 e dezembro de 2006, cujo método de tratamento foi a Análise Fatorial com rotação Varimax. Os resultados auferidos revelaram integração significativa entre os índices de alguns países, formando três grupos: (1) Indonésia, México, Argentina, Índia, Brasil, Japão e Egito; (2) Hong Kong, Estados Unidos, Reino Unido, Alemanha, Holanda e França; e (3) Malásia e Cingapura. Nesta análise, apenas Israel não apresentou relacionamento com as bolsas de valores dos demais países.

Palavras-chave: Integração de mercados acionários. Análise fatorial. Estratégias de diversificação.

\begin{abstract}
The aim of the present work is to evaluate the integration level between the yield rates of the main stock market indexes in the following countries: India, Brazil, Egypt, France, Germany, Hong Kong, Indonesia, Israel, Japan, Malaysia, Argentina, Mexico, Holland, Singapore, the United Kingdom and the United States. The collected data comprehend the period from January, 1998 till December, 2006, and the method of analysis was the Factor Analysis using Varimax Rotation. The obtained results revealed significative integration among
\end{abstract}


the indexes of some countries, and identified three different groups: (1) Indonesia, Mexico, Argentina, India, Brazil, Japan and Egypt; (2) Hong Kong, the United States, the United Kingdom, Germany, Holland and France; (3) Malaysia and Singapore. In this analysis, only Israel did not have any relationship with the other countries stock markets.

Keywords: Stock markets integration. Factor analysis. Diversification strategies.

\section{INTRODUÇÃO}

Como consequência da globalização financeira observada em décadas mais recentes, surgiram estudos acerca do processo de integração internacional de mercados com diversos objetivos - dentre eles a redução do risco na escolha dos portfólios ${ }^{1}$ por meio da diversificação. Pode-se descrever a globalização financeira sob a forma de um fenômeno composto por três dimensões (GONÇALVES, 1996):

1) integração maior entre os sistemas financeiros nacionais, especialmente nos países desenvolvidos, e em menor número nos mercados emergentes. $\mathrm{O}$ progresso nas áreas de informática e telecomunicações facilita a integração financeira internacional;

2) aumento da concorrência relacionada ao sistema financeiro internacional, observado pela disputa crescente de mercados por parte dos bancos de diferentes origens e instituições financeiras não bancárias;

3) o avanço na internacionalização de serviços financeiros - habitantes de um país passam a ter acesso a serviços financeiros oferecidos por outros países - e a criação de novos instrumentos financeiros, novas estratégias de diversificação dos investidores, assim como a própria instabilidade do sistema monetário internacional.

O Brasil pode ser considerado, atualmente, um mercado de interesse para os investidores internacionais, possivelmente como opção para mitigar riscos. Investidores de diferentes países passaram a aplicar recursos significativos em mercados emergentes, buscando carteiras diversificadas.

O investimento internacional é analisado por Bodie, Kane e Marcus (2000) como uma generalização do modo de decisão de escolha da carteira internamente, porém, com maior variedade de ativos para sua constituição. Nesse processo, leva-se em consideração o risco da taxa de câmbio, as restrições sobre os fluxos de capital pelas fronteiras nacionais, $O$ eventual risco político, assim como os regulamentos de cada país, que podem afetar os índices de ações de maneira direta ou indireta.

Utilizando a técnica multivariada de Análise Fatorial, Lessard (1973) estudou o potencial de diversificação internacional de investimentos em um grupo de países em desenvolvimento. Em seu trabalho, analisou a viabilidade da organização de uma União de Investimentos (UI) com desenvolvimento semelhante, em que algum grau de reciprocidade entre os países poderia ser mantido e a perda de soberania seria limitada, com o objetivo de conquistar vantagem no processo de diversificação. Lessard obteve resultados que demonstraram superioridade da diversificação de portfólios da UI em relação a investimentos em um só país.

A busca por novas oportunidades de diversificação de mercados acionários em países emergentes e menos integrados pode ser apoiada por um banco de dados e organizações voltadas para este fim, possibilitando estudos mais elaborados. Uma destas organizações é o International Finance Corporation (IFC), criado em 1956 com o objetivo de promover o investimento do setor privado em nações em desenvolvimento. Possui atualmente 178 países membros, monitora a lucratividade das principais ações negociadas e mantém

\footnotetext{
1 Portfólio, ou carteira de investimentos, pode ser descrito como uma reunião de ativos que proporcionam ao investidor um dado nível de retorno esperado e risco.
} 
índices agregados em séries análogas às existentes sobre mercados desenvolvidos.

Atualmente, os estudos nesse campo têm sido apoiados por técnicas econométricas e estatísticas robustas, com o objetivo de identificar potenciais ganhos em negócios internacionais por meio da diversificação, analisar mercados potencialmente integrados e, a partir daí, desenvolver estratégias de investimento que permitam reduzir as probabilidades de perda em suas aplicações.

O objetivo deste trabalho é avaliar o grau de integração e possibilidade de diversificação entre 16 Bolsas de Valores internacionais, por meio dos seus respectivos índices de mercado acionário, valendo-se do método de Análise Fatorial.

Quando os mercados acionários se tornam mais interligados, aumenta-se o fluxo de bens, serviços e informação, característico do processo de globalização. Maior sincronismo no comportamento dos retornos dos ativos internacionais acarreta aumento de correlação entre eles e diminui a probabilidade de redução do risco total de carteiras globais.

Bracker, Docking e Koch (1999) consideram que a expressão "integração de mercados internacionais de ações" representa uma ampla área de pesquisa em economia e finanças que leva em conta diversos aspectos de inter-relação entre os mercados.

A análise das reações conjuntas das Bolsas de Valores em diferentes mercados acionários, seja numa mesma região econômica ou não, em função de movimentos significativos nos índices de mercado acionários, pode trazer como consequência a redução dos custos de transação e o aumento do fluxo de capitais entre esses mercados, sendo a principal motivação para esta pesquisa.

O presente trabalho encontra-se estruturado em cinco seções: na primeira faz-se esta introdução; na segunda aborda-se a importância e os benefícios do processo de diversificação internacional; na terceira são apresentados os procedimentos metodológicos; na quarta descrevem-se e analisam-se os resultados; e na quinta são feitas algumas considerações pertinentes ao tema estudado.

\section{Os benefícios da diversificação internacional}

Quando se diz que um indivíduo foi vítima do azar, ele é eximido de qualquer responsabilidade pelo acontecido. Entretanto, ao afirmar que o indivíduo teve sorte, negam-lhe os créditos do seu esforço para atingir os objetivos esperados. Bernstein (1997) indaga sobre que certeza se pode ter sobre o ocorrido: o resultado é devido ao acaso ou à escolha feita pelo indivíduo?

Conforme a Moderna Teoria de Portfólios (MTP) (MARKOWITZ, 1952), o retorno esperado de uma carteira é dado pela média dos retornos esperados dos ativos individuais, ponderada por sua respectiva participação individual no conjunto. $\mathrm{O}$ risco da carteira é dado pelo desvio padrão dos retornos, e é função da variância individual de cada ativo, assim como das parcelas das covariâncias entre os ativos.

Atualmente, a concentração de investimentos em ativos com maior retorno esperado é suplantada pelo conceito de diversificação, ajustando o foco das estratégias de investimento. Ainda segundo a MTP, se dois ativos apresentam retornos não correlacionados, há a expectativa de um ganho dado pelo aumento do retorno esperado ou pela redução do risco associado, que é decorrente da distribuição dos investimentos entre aqueles dois ativos. Sob um ponto de vista racional, os investidores buscam estabelecer estratégias de investimento de modo a maximizar os retornos esperados e, ao mesmo tempo, minimizar os seus riscos.

Markowitz (1952) derrubou o conceito ingênuo de diversificação de que bastava distribuir os ovos em diferentes cestos e, quanto maior o número de cestos, menor seria o risco, demonstrando que quando ocorre forte correlação positiva entre os ativos em questão, eles se comportam como um único ativo.

Com a diversificação internacional, esperase garantir melhor desempenho de uma carteira, reduzindo a probabilidade de perdas no decorrer do tempo. Isso é possível a partir de uma combinação entre ativos, cuja correlação seja negativa, para a formação da carteira.

Nos países ditos emergentes, os mercados financeiros têm apresentado mudanças expressivas a partir do início da década de 1990. Entre 1989 e 1992, os investimentos em carteiras de mercados emergentes tiveram seus valores triplicados (MULLIN, 1993). A atratividade pelos mercados de ações dos países emergentes deriva, em parte, de retornos elevados ocorridos nos últimos anos.

Pode-se observar que, à medida que os mercados passam a ter maior proximidade em termos 
econômicos, tendem a movimentar-se de maneira semelhante e a integrar-se, de modo que, em uma eventual crise ou ataque especulativo em um mercado, haverá reflexos diretos nos demais mercados. Assim, não se pode considerar que há diversificação e os investimentos internacionais não apresentam benefícios. Cabe salientar que o investidor dos mercados de capitais internacionais enfrenta dois tipos principais de riscos: o cambial, que está associado à volatilidade da taxa de câmbio da moeda do país onde os fluxos serão gerados, e o risco de não conseguir repatriar os recursos.

O fim do Tratado de Bretton Woods, ocorrido no início da década de 1970, que conduziu à desvalorização de moedas em grandes economias e à livre flutuação das taxas de câmbio, levou ao crescimento do mercado internacional de capitais. Em consequência disso e de diversos outros processos advindos da globalização, a diversificação de mercados aumentou substancialmente a partir do fim da década de 1990 (KRUGMAN; OBSTFELD, 1999).

Em um estudo de diversificação internacional, Bailey e Stulz (1990) analisaram o efeito da inserção de ativos negociados nos seguintes mercados: Austrália, Coreia do Sul, Filipinas, Hong Kong, Japão, Tailândia, Taiwan e Cingapura. Como resultado, os autores observaram benefícios expressivos para portfólios diversificados, ao verificar que investidores americanos com ativos cotados no índice S\&P 500 teriam reduzido seu risco em cerca de um terço, se tivessem incluído ativos negociados em mercados do Pacífico.

Para Damodaran e Bernstein (2000), os investidores devem avaliar seus investimentos em função dos riscos relacionados, levando em consideração o prêmio pelo risco local que se espera receber ao se compor uma carteira ótima, tendo em conta o fato de que os retornos serão em moeda local.

Mishkin (2000), por sua vez, considera que a diversificação pode beneficiar os mercados emergentes, ajudando, mesmo que não diretamente, a financiar investimentos e o déficit orçamentário de seus governos.

É importante enfatizar que a abertura financeira dos mercados e a sua consequente integração podem gerar problemas sistêmicos nas economias, independentemente da implantação de reformas. Apesar de fundamental, a adoção de políticas macroeconômicas prudentes não garante a sustentabilidade dos fluxos de capitais.
A montagem de portfólios ou carteiras tem por objetivo a redução do risco diversificável. Para que esse processo seja efetivo, os ativos internacionais, mais especificamente aqueles negociados nos diversos mercados acionários, devem apresentar correlação suficientemente baixa (próxima de zero), ou negativa, de modo a permitir uma redução significativa do risco do portfólio. Logo, a existência do risco diversificável é de vital importância na determinação da taxa requerida pelo investidor.

\section{PROCEDIMENTOS METODOLÓGICOS}

Nesta seção, apresenta-se a metodologia utilizada no trabalho, sendo subdividida em três subseções que retratam a forma como foram coletados os dados, o seu tratamento, a caracterização desta pesquisa e o método de análise utilizado.

\section{Coleta dos dados}

Os dados foram obtidos do site do Yahoo Finance (2006). Foram coletadas séries temporais mensais de fechamento das Bolsas de Valores do Brasil, Argentina, México, Estados Unidos, Hong Kong, Índia, Indonésia, Malásia, Japão, Cingapura, França, Alemanha, Holanda, Reino Unido, Egito e Israel. As variáveis coletadas e os respectivos índices acionários encontram-se descritos no Quadro 1.

Os dados coletados referem-se ao período compreendido entre janeiro de 1998 e dezembro de 2006, perfazendo um total de 108 observações para cada índice acionário.

O período considerado é consequência da disponibilidade de dados, concomitante para todos os índices. Desse modo, os índices descritos no Quadro 1 foram obtidos por meio de amostragem não probabilística por acessibilidade, isto é, em função de os indicadores estarem disponíveis nas fontes consultadas e em períodos comuns.

As séries temporais coletadas foram ajustadas para uma mesma base (valores constantes) tendo como referência o mês de janeiro de 1998, com o objetivo de estabelecerem-se comparações. O processamento das informações coletadas foi realizado com base nos softwares XLStat versão 7.5 e Statistica for Windows versão 7.0. 
QUADRO 1 - Índices das Bolsas de Valores pesquisadas

\begin{tabular}{llll}
\hline Países & Índices das Bolsas de Valores & Países & Índices das Bolsas de Valores \\
\hline 1. Brasil & Ibovespa Index & 9. Japão & Nikkei 225 Index \\
2. Argentina & Merval Index & 10. Cingapura & Straits Times Indu \\
3. México & México Bolsa Index & 11. França & CAC 40 Index \\
4. Estados Unidos & S\&P500 Index & 12. Alemanha & DAX Index \\
5. Hong Kong & Hong Seng Stock Index & 13. Holanda & Amsterdã Exchange Index \\
6. Índia & BSE 30 Index & 14. Reino Unido & FTSE 100 Index \\
7. Indonésia & Jakarta Composite & 15. Egito & CMA Index \\
8. Malásia & Kuala Lumpur Composite Index & 16. Israel & TA-100 Index \\
\hline
\end{tabular}

\section{Caracterização da pesquisa}

A pesquisa, segundo Jung (2004, p. 142), "é usada como instrumento ou ferramenta para a descoberta de novos conhecimentos", enquanto que "o desenvolvimento é a aplicação, através de processos, destes novos conhecimentos para se obter resultados práticos".

Hair Jr. etal. (2005, p. 31) definem a pesquisa em Administração como "uma função em busca da verdade que reúne, analisa, interpreta e relata informações, de modo que as decisões administrativas se tornem mais eficazes".

Este trabalho caracteriza-se como uma pesquisa quantitativa de natureza descritiva, cujos dados descrevem eventos ao longo do tempo. $\mathrm{Na}$ visão de Hair Jr. et al. (2005, p. 88), os estudos descritivos longitudinais são adequados quando as questões de pesquisa e hipóteses são afetadas pela variação das coisas com o decorrer do tempo, o que permite mapear elementos cujas tendências sejam observáveis.

\section{Método de análise: Análise Fatorial}

A Análise Fatorial é um conjunto de métodos da estatística multivariada que permite, em dadas situações, explicar o comportamento de um grande número de variáveis observáveis em termos de um pequeno número de fatores, ou variáveis não observáveis. Pode ser usada como técnica estatística exploratória que consiste essencialmente em reescrever as coordenadas das amostras em outro sistema de eixos, mais conveniente para a análise dos dados. Isto é, um conjunto de $n$ variáveis originais gera, por meio de suas combinações lineares, $k$ fatores, cuja principal característica é a ortogonalidade.

É conveniente que o peso de cada fator seja escolhido de tal forma que o primeiro fator seja aquele que explica a maior parcela da variação total. Procede-se de modo semelhante para se determinar o segundo fator, observando que este não seja correlacionado com o anterior. Para os demais fatores, o processo é o mesmo. Assim, os fatores são estimados de modo que seus coeficientes não sejam correlacionados, enquanto que os valores das variáveis originais podem sê-lo.

A análise consiste, portanto, em obter os autovetores e correspondentes autovalores da matriz de covariâncias. Nessa matriz, que é simétrica, os elementos principais da diagonal são as variâncias entre as variáveis, e os demais elementos representam as covariâncias dos pares de variáveis.

Deve-se selecionar o número de fatores a serem mantidos para a análise. São levados em conta os autovalores para auxiliar na seleção do número de fatores. Em geral, os pacotes estatísticos estabelecem como padrão o critério da raiz latente, pelo qual são considerados aqueles fatores cujo autovalor é igual ou superior à unidade (HAIR Jr. et al., 2005). 
Neste ponto é necessário analisar a matriz fatorial não rotacionada. A soma dos quadrados das cargas fatoriais de cada fator corresponde ao seu autovalor, enquanto que a soma de quadrados das cargas fatoriais de cada variável corresponde à sua comunalidade, ou seja, quanto da sua variância é comum às demais variáveis consideradas na análise, com base no número escolhido de fatores.

Para se obter um padrão fatorial mais simples e mais significativo, é necessário proceder à rotação da matriz fatorial, que consiste em redistribuir a variância dos primeiros fatores para os últimos. A rotação mais conhecida e apropriada para este caso de estudo é a rotação ortogonal Varimax.

\section{Apresentação e análise dos dados e resultados}

Conforme descrito na primeira seção, o presente trabalho tem como objetivo identificar o grau de integração ou de inter-relação entre as taxas de rentabilidade dos índices de ações das Bolsas de Valores de um conjunto de países.

Para atingir essa meta, inicialmente são calculadas as taxas discretas das rentabilidades mensais dos índices de ações dos países selecionados, no período considerado. Os preços de fechamento de tais índices foram transformados em taxas de variação ou de rentabilidades por meio da expressão (1):

$$
R_{t}=\left[\left(\frac{P_{t}}{P_{t-i}}\right)-1\right] \times 100 \quad \text { com: } i=1,2, \ldots, n
$$

Onde:

$\mathrm{R}_{\mathrm{t}}$ : taxa de rentabilidade do índice de ações no período t;

$\mathrm{P}_{\mathrm{t}-\mathrm{i}}:$ preço de fechamento do índice de ações no período t-i;

$\mathrm{P}_{\mathrm{t}}$ : preço de fechamento do índice de ações no período t.

Em seguida, obtiveram-se as estatísticas descritivas dos índices de ações estudados para avaliar as suas rentabilidades médias (médias aritméticas anuais dos índices) e suas respectivas volatilidades ou riscos (representadas aqui pelo desvio-padrão). Os dados relativos ao retorno e ao risco estão descritos na Tabela 1.

Considerando que os deslocamentos de recursos têm sua lógica na busca de taxas de retornos mais elevados, infere-se que as carências de capital dos países emergentes podem ser sanadas, em parte, pela entrada de recursos externos, o que permite, em parte, ser traduzido na redução das disparidades sociais. Contudo, apesar dos riscos e incertezas rondarem quase que instantaneamente as economias mundiais, em razão do grande fluxo de capitais especulativos, isto pode resultar em perdas irreparáveis para alguns indivíduos, empresas ou até mesmo países.

A crise asiática, iniciada em julho de 1997, provocou danos para toda a economia mundial, pois se refletiu durante todo o ano de 1998, especialmente nos países em desenvolvimento, conforme se observa na Tabela 1 . O efeito inicial da crise na Ásia teve como consequência imediata a transferência de ativos financeiros diretos e de curto prazo, em especial do Brasil, que começou a sentir os primeiros sinais de um retraimento dos capitais, o que levou o governo brasileiro a elevar a taxa de juros e a anunciar uma série de medidas de cunho fiscal, com o objetivo de amenizar os efeitos provocados no sistema econômico.

Ainda avaliando a Tabela 1, é visível que o ano de 1998 foi marcado por uma forte instabilidade econômico-financeira, em consequência do pedido de moratória da Federação Russa, que provocou perdas significativas aos credores de diversos países que lá aplicavam - com destaque maior, na Europa, para a Alemanha. Aliada à grande crise de governabilidade política e a uma grande desvalorização da moeda russa, houve uma retração nas aplicações e nas linhas de crédito colocadas à disposição dos países emergentes, o que provocou uma crise de confiança em todo sistema financeiro mundial.

Neste período, os retornos médios mensais esperados para os investidores dispostos a encarar as turbulências financeiras ocorridas na Rússia, foram corroídos pelos efeitos desse ataque especulativo. Índia, Brasil, Hong Kong, Indonésia, Japão, Malásia, Argentina, México e Cingapura apresentaram retornos médios mensais negativos, ou seja, houve perdas em suas Bolsas de Valores, com graus de risco elevados.

Convém observar que, neste mesmo ano, o Brasil obteve um empréstimo junto ao 
TABELA 1 - Taxas médias de rentabilidade e risco dos índices (dados em \%)

\begin{tabular}{|c|c|c|c|c|c|c|c|c|c|c|c|c|c|c|c|c|c|}
\hline \multicolumn{2}{|c|}{ Países } & . & 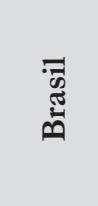 & $\begin{array}{l}\stackrel{0}{\mathscr{L}_{0}} \\
{[1]}\end{array}$ & 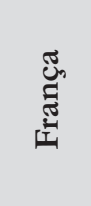 & 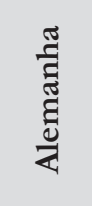 & 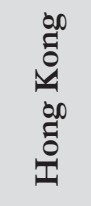 & 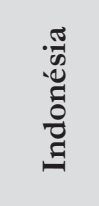 & $\begin{array}{l}\overline{\mathscr{\Xi}} \\
\stackrel{\tilde{\omega}}{\omega}\end{array}$ & 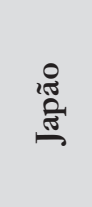 & 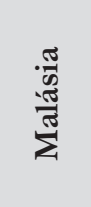 & 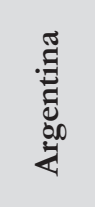 & $\frac{0}{\stackrel{0}{x}}$ & 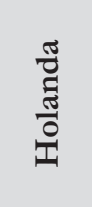 & 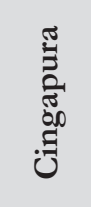 & 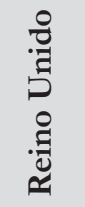 & $\underset{S}{\overleftrightarrow{S}}$ \\
\hline \multirow{2}{*}{$\stackrel{\infty}{\stackrel{2}{\sigma}}$} & Ret. & $-1,17$ & $-2,21$ & 0,57 & 2,56 & 1,47 & $-0,34$ & $-0,04$ & 0,24 & $-0,58$ & $-0,07$ & $-2,52$ & $-2,09$ & 2,31 & $-0,58$ & 1,27 & 2,26 \\
\hline & Ris. & 6,81 & 12,93 & 3,97 & 9,74 & 9,48 & 7,63 & 9,58 & 5,19 & 5,02 & 8,96 & 10,26 & 10,44 & 8,87 & 10,56 & 5,55 & 7,07 \\
\hline \multirow{2}{*}{ बे } & Ret. & 3,77 & 6,67 & 6,04 & 5,46 & 3,70 & 3,52 & 3,22 & 5,13 & 2,09 & 1,86 & 1,18 & 5,21 & 2,48 & 4,60 & 1,78 & 2,10 \\
\hline & Ris. & 7,71 & 9,06 & 5,47 & 7,68 & 9,06 & 7,06 & 7,78 & 7,09 & 3,15 & 7,26 & 6,06 & 8,49 & 5,95 & 7,28 & 4,41 & 5,22 \\
\hline \multirow{2}{*}{ ڤ్రి } & Ret. & $-2,00$ & $-1,19$ & $-0,06$ & $-0,09$ & $-0,99$ & $-0,95$ & $-3,01$ & 0,20 & $-2,11$ & $-1,09$ & $-1,31$ & $-2,43$ & $-0,63$ & $-2,34$ & $-1,20$ & $-1,30$ \\
\hline & Ris. & 7,38 & 10,72 & 6,74 & 8,66 & 8,93 & 7,38 & 5,28 & 15,17 & 5,84 & 5,87 & 4,70 & 11,51 & 6,45 & 8,09 & 5,82 & 7,35 \\
\hline \multirow{2}{*}{ ఠ్రి } & Ret. & $-1,37$ & $-1,09$ & $-0,23$ & $-3,53$ & $-2,41$ & $-1,88$ & $-0,28$ & $-1,31$ & $-1,33$ & 0,14 & $-1,19$ & 1,18 & $-2,44$ & $-1,28$ & $-1,71$ & $-1,50$ \\
\hline & Ris. & 6,59 & 10,72 & 4,22 & 10,97 & 10,24 & 6,10 & 4,32 & 12,23 & 3,44 & 4,83 & 7,53 & 9,78 & 7,00 & 7,12 & 4,75 & 7,23 \\
\hline \multirow{2}{*}{ ญิ } & Ret. & 0,22 & $-1,50$ & 0,56 & $-4,23$ & $-4,29$ & $-1,06$ & 0,38 & $-3,13$ & $-0,80$ & $-0,41$ & 2,25 & $-0,40$ & $-3,44$ & $-1,20$ & $-2,17$ & $-2,34$ \\
\hline & Ris. & 4,38 & 8,80 & 1,73 & 9,42 & 9,15 & 3,40 & 5,05 & 6,85 & 2,99 & 3,55 & 6,61 & 8,07 & 8,88 & 4,77 & 5,13 & 5,87 \\
\hline \multirow{2}{*}{ ڤิ̊ } & Ret. & 4,76 & 7,10 & 4,20 & 1,34 & 2,03 & 1,66 & 3,08 & 5,53 & 0,86 & 1,21 & 5,36 & 4,39 & 0,28 & 1,79 & 0,91 & 2,03 \\
\hline & Ris. & 6,80 & 7,65 & 3,67 & 5,41 & 5,50 & 2,61 & 4,56 & 8,05 & 2,18 & 3,15 & 5,95 & 4,25 & 4,82 & 2,59 & 3,46 & 3,16 \\
\hline \multirow{2}{*}{ ఫ્ઠ } & Ret. & 1,48 & 2,56 & 10,44 & 0,71 & 0,55 & 0,84 & 3,56 & 2,78 & 0,33 & 0,93 & 2,97 & 6,78 & 0,19 & 1,28 & 0,57 & 0,87 \\
\hline & Ris. & 8,69 & 9,17 & 9,41 & 2,15 & 2,78 & 3,81 & 6,22 & 7,46 & 2,05 & 3,35 & 12,28 & 8,03 & 2,27 & 2,13 & 1,67 & 2,50 \\
\hline \multirow{2}{*}{ ֻัڤ్ } & Ret. & 5,41 & 4,70 & 25,43 & 2,42 & 2,18 & 0,33 & 1,88 & 5,12 & 1,89 & $-0,06$ & 1,65 & 8,03 & 1,66 & 1,19 & 1,37 & 0,32 \\
\hline & Ris. & 11,55 & 15,50 & 24,40 & 4,32 & 3,66 & 3,35 & 7,85 & 7,40 & 2,90 & 2,36 & 13,31 & 15,96 & 3,15 & 3,18 & 2,46 & 2,83 \\
\hline \multirow{2}{*}{ ષั่ } & Ret. & 7,71 & 6,56 & 2,66 & 2,08 & 2,17 & 2,08 & 6,63 & 3,26 & 0,27 & 1,32 & 4,90 & 12,86 & 1,06 & 2,33 & 0,99 & 1,55 \\
\hline & Ris. & 15,44 & 17,45 & 58,54 & 4,31 & 3,70 & 3,01 & 10,60 & 11,62 & 3,00 & 2,95 & 15,83 & 19,19 & 2,94 & 4,73 & 2,74 & 2,28 \\
\hline
\end{tabular}

Nota: Ret. $=$ Rentabilidade e Ris. $=$ Risco.

Fundo Monetário Internacional (FMI) da ordem de US\$ 41,5 bilhões. Para Carvalho e Silva (2000, p. 260), essa operação foi necessária devido ao temor dos investidores norte-americanos, que experimentaram contínuas perdas no mercado latino-americano, bem como em outros países continentais.

Em janeiro de 1999, o Brasil foi obrigado a desvalorizar a sua moeda, em razão de ter sido afetada pelas crises financeiras anteriores, passando a trabalhar com uma taxa de câmbio flutuante. A moeda brasileira perdeu cerca de um terço do seu valor em relação ao dólar norte-americano. Notadamente, o Brasil passou por essas crises em consequência de abalos financeiros provocados ou induzidos externamente, reforçados por erros econômicos próprios e por desequilíbrios acumulados nas contas internas. 
Destaca-se também que nenhuma das crises mencionadas alterou significativamente a qualidade e a direção da política externa brasileira, mas todas elas influenciaram de alguma forma os elementos de política econômica interna. Apesar de tantas adversidades no mercado internacional, os retornos médios mensais foram positivos no ano de $1999 \mathrm{em}$ todo o grupo estudado.

No ano de 2000, foram experimentadas expressivas quedas, especialmente nos seguintes países: Índia, Indonésia, Japão, México e Cingapura, cujas perdas ultrapassaram $2 \%$. Somente Israel apresentou resultado positivo. Verificou-se também uma elevada volatilidade nos índices acionários do Brasil, de Israel e do México. No Brasil, houve uma elevada pressão na taxa de câmbio (R $\$ / U S \$)$, em razão do pessimismo e das incertezas da economia norte-americana, que na época apresentava sinais de recessão, além dos desdobramentos da iminente crise na Argentina.

Em 2001, as Bolsas de Valores dos países estudados comportaram-se de forma semelhante ao ano 2000. Pode-se inferir que houve um reflexo da situação em anos anteriores, assim como um forte impacto causado pelos ataques terroristas em Nova Iorque, em 11 de setembro daquele ano, seguido pela ofensiva militar liderada pelos Estados Unidos no Afeganistão.

Segundo estimativas de seguradoras, os prejuízos somaram entre US\$ 30 bilhões e US\$ 60 bilhões de dólares em prejuízos materiais. Entretanto, eles podem ter sido maiores, se forem consideradas as perdas relativas aos negócios cancelados e as empresas paralisadas em consequência de tais ocorrências.

Nesse mesmo ano, a Argentina experimentou talvez o pior período recessivo de sua história. Enquanto isso, no Brasil, ocorreu a crise energética e a desvalorização da moeda em relação ao dólar norte-americano, em torno de $20 \%$.

O ano de 2002 apresentou resultados piores que 2001, apesar de especialistas como Koen (2002) declararem que a economia mundial não tenha caído tanto e nem por tanto tempo como se esperava inicialmente, naquele período. A economia provavelmente teria crescido mais se os atentados de 11 de setembro de 2001 não tivessem ocorrido, mas Koen acredita que os impactos foram superestimados.

O ano de 2002 foi marcado também pelo início da circulação do euro como moeda comum na Europa. Houve uma retração na economia norteamericana depois de uma década de forte expansão. No Brasil, o real teve a pior relação de paridade com o dólar, que chegou a valer $\mathrm{R} \$ 4,00$. O Risco Brasil oscilou entre 600 e 2.500 pontos, fazendo com que as linhas de crédito internacionais se afastassem, e o País ficasse impossibilitado de captar recursos estrangeiros.

O panorama conjuntural em 2003 foi marcado por uma forte oposição de diversos países e da própria ONU à invasão no Iraque. Mesmo assim, os Estados Unidos e a Grã-Bretanha lideraram essa ofensiva militar. Nestor Kirchner assumiu a presidência da Argentina, com a moratória decretada desde 2001, propondo a renegociação de uma dívida de US\$ 70 milhões, pedindo redução de juros devidos e dilação nos prazos de pagamento. Ao contrário do que previram alguns especialistas, o mercado manteve confiança no país, cuja Bolsa de Valores obteve uma das maiores altas.

Retorno ainda maior foi experimentado pelo Brasil, que também contou com a confiança dos investidores, com queda no Risco País, e teve um crescimento médio mensal acima de $7 \%$ no índice Bovespa. O ano de 2003 foi um dos melhores para as Bolsas de Valores dos países estudados no presente trabalho.

Os retornos dos índices das Bolsas de Valores analisadas se comportaram de modo parecido nos anos de 2004 e 2005, com destaque para o Egito, com rentabilidade média acima de 10\% e $25 \%$ respectivamente. Cabe destacar que na Bolsa do México, o seu índice acionário "IPC" registrou ganho médio próximo de 7\% nos dois anos.

A conjuntura econômica vivenciada em 2004 mostrou que as antigas repúblicas soviéticas aumentaram o bloco da União Européia de 15 para 25 países, passando a formar um mercado de 450 milhões de habitantes, enquanto o Brasil registrou uma das maiores taxas de desemprego entre os países emergentes. Ainda naquele ano o preço do petróleo superou a marca histórica de U\$ 50,00 por barril, graças, em parte, ao aumento do consumo, com destaque para a China.

A taxa de juros Selic, em 2004, variou entre $16 \%$ e $17,75 \%$ ao ano e, em 2005 , chegou a $19,75 \%$ a.a., encerrando o período com $18 \%$ a.a. As altas taxas de juros pagas pelo Brasil podem ser consideradas um importante atrativo aos investidores estrangeiros. O mercado pareceu não perceber a série de crises 
políticas e institucionais pelas quais passou o governo brasileiro em 2005, e o índice Bovespa teve retorno médio superior a 2\% em 2004 e situou-se próximo de $5 \%$ em 2005.

Em 2005, as Bolsas de Valores de Hong Kong, Malásia e Estados Unidos tiveram taxas de rentabilidades médias praticamente nulas, enquanto que os demais países analisados obtiveram retornos positivos razoáveis.

As taxas de retornos dos índices dos países analisados apresentaram ganhos menores em 2006 que nos anos de 2004 e 2005. O fato de destaque no ano de 2006 refere-se à Bolsa de Valores do México, cuja rentabilidade média situou-se acima dos 12\%, seguida pela da Índia, do Brasil e da Indonésia, com taxas de rentabilidade de $7,71 \%, 6,56 \%$ e $6,63 \%$, respectivamente - conforme indicado na Tabela 1 .

Destaca-se ainda que, no ano de 2006, o Brasil teve um baixo crescimento econômico. Houve aumento do desemprego e uma queda na renda. A Bovespa quebrou diversas vezes o recorde de pontuação, passando dos 44 mil pontos, fechando o ano com volume financeiro de mais de $\mathrm{R} \$ 2,2$ bilhões, enquanto o dólar norte-americano teve queda em termos nominais de $7,7 \%$ no ano.

As constantes crises vivenciadas nos países emergentes, em razão das desvalorizações das suas moedas e da ausência dos investidores estrangeiros durante o período analisado, são notórias, principalmente após a crise asiática em julho de 1997. Desde então, até o ano de 2002, esses mercados de capitais passaram por dificuldades, mesmo com boa parte dos países tendo realizado reformas estruturais que melhoraram significativamente as suas economias. A partir do ano de 2003, observou-se uma expressiva recuperação vivenciada até o fim de 2006 nas economias dos países pesquisados.

\section{ANÁLISE DOS RESULTADOS}

Com o objetivo de determinar se os movimentos dos mercados acionários analisados encontram-se relacionados, foram estimados os coeficientes de correlação de Pearson entre os índices estudados, identificando, a partir disso, a possibilidade de retornos adicionais por meio do processo de diversificação. A Tabela 2 revela que alguns mercados de capitais avaliados fornecem um potencial elevado de diversificação para melhorar o desempenho ajustado pelo risco de uma carteira meramente doméstica, uma vez que possuem alguns coeficientes de correlação relativamente baixos, considerando significância estatística de 5\%.

TABELA 2 - Matriz de Correlação de Pearson das taxas de rentabilidade dos ativos

(continua)

\begin{tabular}{|c|c|c|c|c|c|c|c|c|c|c|c|c|c|c|c|c|}
\hline Países & 孚 & 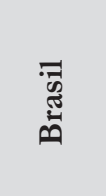 & 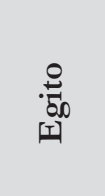 & 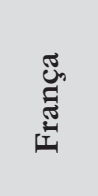 & 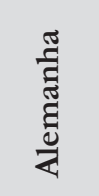 & 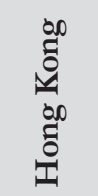 & 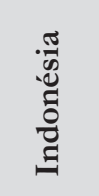 & $\begin{array}{l}\overline{\widetilde{\varpi}} \\
\stackrel{\vec{\omega}}{\oplus}\end{array}$ & 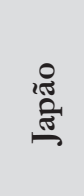 & $\frac{\frac{\pi}{5}}{\frac{\pi}{\pi}}$ & 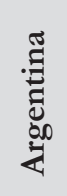 & $\begin{array}{l}\frac{\dot{U}}{x} \\
\sum_{\Sigma}^{0}\end{array}$ & $\begin{array}{l}\frac{\pi}{0} \\
\frac{\pi}{\tilde{J}} \\
0 \\
\text { I }\end{array}$ & 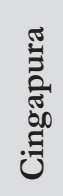 & 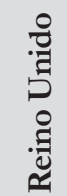 & 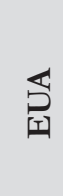 \\
\hline Índia & 1 & & & & & & & & & & & & & & & \\
\hline Brasil & 0,524 & 1 & & & & & & & & & & & & & & \\
\hline Egito & 0,326 & 0,338 & 1 & & & & & & & & & & & & & \\
\hline França & 0,279 & 0,518 & 0,165 & 1 & & & & & & & & & & & & \\
\hline Alem & 0,282 & 0,556 & 0,152 & 0,910 & 1 & & & & & & & & & & & \\
\hline Hong & 0,345 & 0,600 & 0,135 & 0,534 & 0,556 & 1 & & & & & & & & & & \\
\hline Indon & 0,503 & 0,426 & 0,312 & 0,338 & 0,389 & 0,328 & 1 & & & & & & & & & \\
\hline Israel & 0,360 & 0,426 & 0,203 & 0,379 & 0,399 & 0,378 & 0,278 & 1 & & & & & & & & \\
\hline Japão & 0,413 & 0,519 & 0,246 & 0,456 & 0,477 & 0,412 & 0,441 & 0,355 & 1 & & & & & & & \\
\hline
\end{tabular}


TABELA 2 - Matriz de Correlação de Pearson das taxas de rentabilidade dos ativos

\begin{tabular}{|c|c|c|c|c|c|c|c|c|c|c|c|c|c|c|c|c|}
\hline Países & 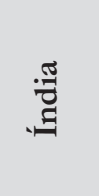 & 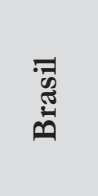 & $\begin{array}{l}\stackrel{8}{\circ 0} \\
\text { [I工 }\end{array}$ & 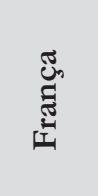 & 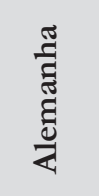 & $\begin{array}{l}b_{0}^{0} \\
\tilde{0} \\
0 \\
0 \\
0 \\
0 \\
0\end{array}$ & 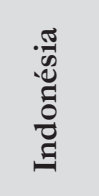 & $\begin{array}{l}\overline{\mathscr{U}} \\
\stackrel{\tilde{\omega}}{\omega}\end{array}$ & 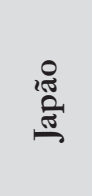 & $\begin{array}{l}\frac{\pi}{\pi} \\
\frac{\pi}{\pi} \\
\frac{\pi}{\pi} \\
\sum\end{array}$ & 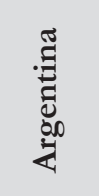 & 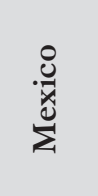 & 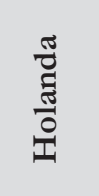 & 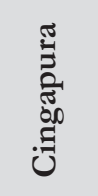 & 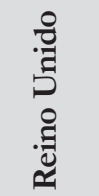 & $\underset{S}{\overleftrightarrow{S}}$ \\
\hline Mala & 0,280 & 0,288 & 0,126 & 0,257 & 0,362 & 0,470 & 0,398 & 0,183 & 0,206 & 1 & & & & & & \\
\hline Argen & 0,433 & 0,610 & 0,272 & 0,268 & 0,328 & 0,394 & 0,400 & 0,307 & 0,293 & 0,312 & 1 & & & & & \\
\hline Mex & 0,627 & 0,717 & 0,417 & 0,460 & 0,512 & 0,589 & 0,594 & 0,389 & 0,470 & 0,375 & 0,665 & 1 & & & & \\
\hline Hol & 0,279 & 0,468 & 0,152 & 0,899 & 0,871 & 0,541 & 0,372 & 0,362 & 0,443 & 0,322 & 0,243 & 0,476 & 1 & & & \\
\hline Sing & 0,417 & 0,496 & 0,137 & 0,469 & 0,490 & 0,730 & 0,512 & 0,297 & 0,395 & 0,530 & 0,428 & 0,583 & 0,534 & 1 & & \\
\hline Rein & 0,261 & 0,559 & 0,157 & 0,801 & 0,765 & 0,610 & 0,397 & 0,323 & 0,487 & 0,272 & 0,317 & 0,512 & 0,835 & 0,569 & 1 & \\
\hline EUA & 0,281 & 0,580 & 0,110 & 0,740 & 0,755 & 0,629 & 0,406 & 0,353 & 0,502 & 0,377 & 0,322 & 0,554 & 0,712 & 0,600 & 0,813 & 1 \\
\hline
\end{tabular}

Nota: Os valores em negrito são significativamente diferentes de 0 com significância de alfa $=5 \%$.

Os valores dos ativos negociados por empresas locais nas Bolsas de Valores tendem a variar em conjunto com indicadores econômicos nacionais, tais como as oscilações da oferta monetária, taxa de juros, modificações das políticas econômicas, bem como as variações das taxas de crescimento da economia.

Apesar de encontrar coeficientes de correlação positivos cujo valor mínimo foi de 0,11 entre Egito e Estados Unidos, e com valor máximo de 0,91 entre França e Alemanha, pode-se inferir que esses mercados ainda oferecem um potencial significativo de redução de riscos via processo de diversificação, quando avaliados sob a ótica da Moderna Teoria de Carteiras.

Ademais, a análise de correlação linear é utilizada como método de averiguação do grau de integração dos mercados financeiros. Aplicou-se ainda a técnica de Análise Fatorial, empregando-se inicialmente o critério da raiz latente para a extração dos fatores, que consiste em incluir somente aqueles cujos autovalores sejam iguais ou superiores à unidade.

Seguindo recomendações evidenciadas na teoria estatística, aplicou-se o método de rotação ortogonal Varimax padronizada, apresentado na terceira seção.
A Figura 1 mostra os fatores das taxas de retorno dos índices de ações após a aplicação da rotação Varimax padronizada. O comportamento do carregamento fatorial, após a utilização da rotação supracitada, visa a explicar o comportamento das variáveis analisadas e não somente dos fatores subjacentes. A partir dos fatores obtidos, pode-se depreender a formação de quatro blocos de Bolsas de Valores distintos, a saber:

- o primeiro bloco, caracterizado pelo primeiro fator, é formado pelas taxas de retorno dos índices das Bolsas de Valores de Hong Kong, Estados Unidos, Reino Unido, Alemanha, Holanda e França;

- o segundo bloco é composto por Indonésia, México, Argentina, Brasil, Índia, Japão e Egito;

- o terceiro bloco compreende as taxas de rentabilidades dos índices das Bolsas de Valores da Malásia e de Cingapura;

- o quarto bloco ficou representado pelas taxas de rentabilidades do índice da Bolsa de Valores de Israel, independente de todos os demais. 


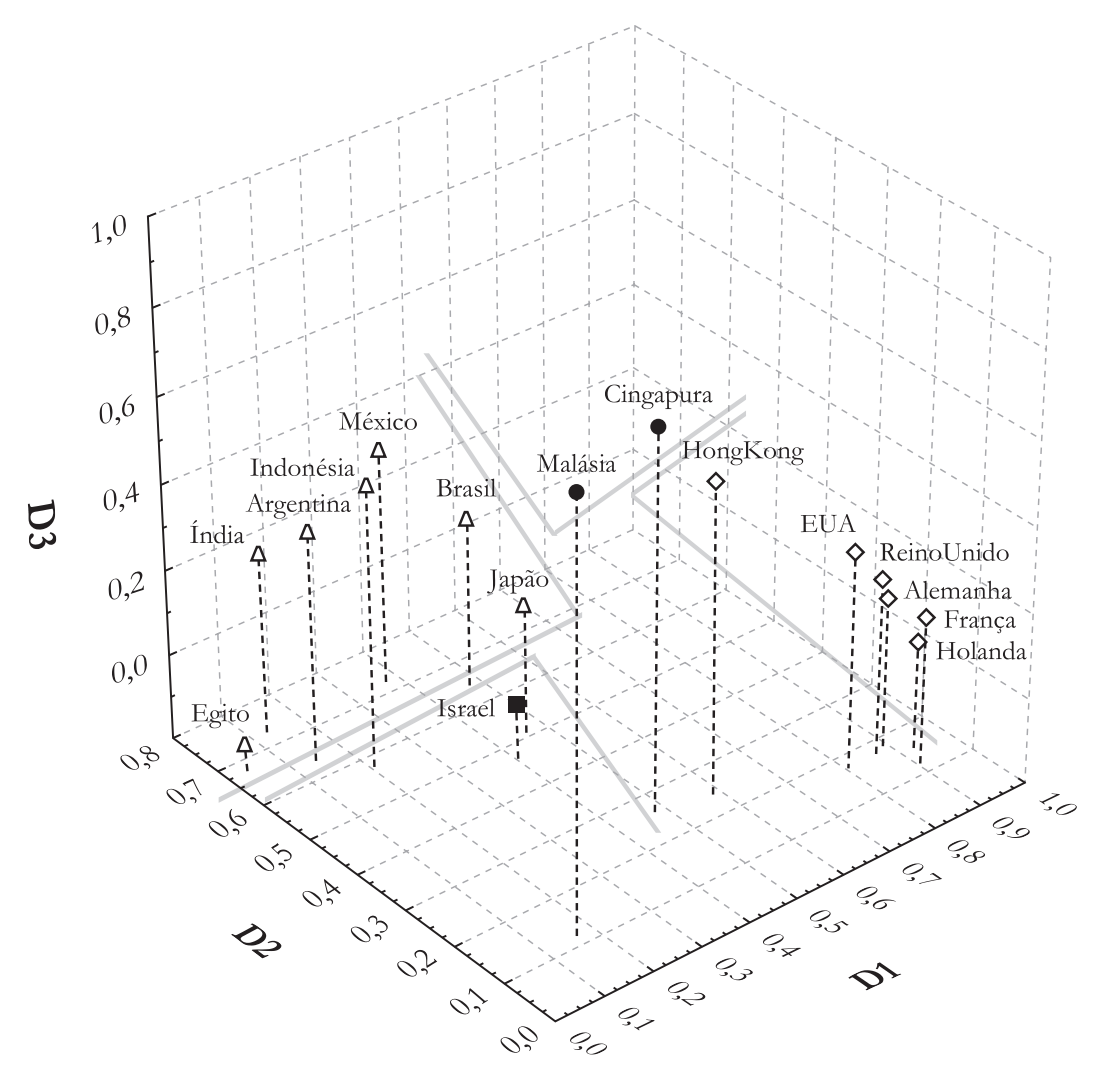

FIGURA 1 - Fatores relacionados às rentabilidades dos índices após a rotação Varimax

Nota: Criado no Statistica for Windows Versão 7.0

Nota-se que existe a possibilidade de obtenção de ganhos potenciais a partir do processo de diversificação de carteiras, investindo-se não somente em um único país ou grupo de países, mas se pulverizando os investimentos nos diferentes blocos. As contribuições, em termos de variabilidade das cargas fatoriais dos índices de mercado de ações rotacionadas e não rotacionadas, encontram-se na Tabela 3.

$\mathrm{Na}$ Tabela 3, percebe-se que no primeiro fator sem rotação $\left(F_{1}\right)$, as únicas Bolsas de Valores sem contribuição estatisticamente significativas são Egito e Malásia. No segundo fator $\left(\mathrm{F}_{2}\right)$ não aparecem contribuições significativas, e no terceiro fator $\left(\mathrm{F}_{3}\right)$ destaca-se somente a Bolsa de Valores da Malásia.
As taxas de retorno do índice de mercado do Egito são representadas por algum fator além do terceiro. Consideraram-se significativas as contribuições ou variabilidades maiores ou iguais a $55 \%$ - que são apresentadas em negrito na Tabela 3.

É possível inferir que a escolha entre carteiras atrativas ou não recai naquela combinação de retorno esperado e risco que, embora envolva uma relação de trade-off, acaba representando uma composição satisfatória para os níveis de aversão ao risco por parte do investidor.

A partir dos riscos e rentabilidades calculados e dos quatro blocos formados pela Análise Fatorial, foram consideradas quatro carteiras para fins de simulação. 
NOGAS, P. S. M.; SILVA, W. V.; DUCLÓS, L. C.

TABELA 3 - Cargas fatoriais das rentabilidades dos índices de ações

\begin{tabular}{lcccccc}
\hline & \multicolumn{7}{c}{ Fatores } \\
\cline { 2 - 7 } Países & \multicolumn{7}{c}{ Sem rotação } & \multicolumn{3}{c}{ Com rotação Varimax } \\
\cline { 2 - 7 } & $\mathbf{F}_{1}$ & $\mathbf{F}_{2}$ & $\mathbf{F}_{3}$ & $\mathbf{D}_{1}$ & $\mathbf{D}_{2}$ & $\mathbf{D}_{3}$ \\
\hline Índia & $\mathbf{0 , 5 7 0 9}$ & 0,5193 & $-0,0942$ & 0,1323 & $\mathbf{0 , 7 3 3 1}$ & 0,2224 \\
Brasil & $\mathbf{0 , 7 7 9 9}$ & 0,2362 & $-0,1550$ & 0,4782 & $\mathbf{0 , 6 4 6 5}$ & 0,2035 \\
Egito & 0,3312 & 0,4754 & $-0,3949$ & 0,0434 & $\mathbf{0 , 6 8 3 3}$ & $-0,1510$ \\
França & $\mathbf{0 , 8 0 5 4}$ & $-0,4449$ & $-0,2082$ & $\mathbf{0 , 9 2 9 0}$ & 0,1543 & 0,0552 \\
Alemanha & $\mathbf{0 , 8 3 1 4}$ & $-0,3847$ & $-0,1235$ & $\mathbf{0 , 8 9 3 2}$ & 0,1835 & 0,1519 \\
Hong Kong & $\mathbf{0 , 7 7 1 1}$ & $-0,0876$ & 0,2739 & $\mathbf{0 , 5 7 7 9}$ & 0,2363 & 0,5362 \\
Indonésia & $\mathbf{0 , 6 3 2 5}$ & 0,3908 & 0,1685 & 0,2010 & $\mathbf{0 , 5 7 0 8}$ & 0,4637 \\
Israel & $\mathbf{0 , 5 2 4 6}$ & 0,1014 & $-0,3258$ & 0,4053 & 0,4712 & $-0,0731$ \\
Japão & $\mathbf{0 , 6 5 7 0}$ & 0,1241 & $-0,1966$ & 0,4634 & $\mathbf{0 , 5 1 0 9}$ & 0,0995 \\
Malásia & 0,5038 & 0,1182 & $\mathbf{0 , 6 4 3 6}$ & 0,1684 & 0,1205 & $\mathbf{0 , 7 9 9 4}$ \\
Argentina & $\mathbf{0 , 5 7 6 5}$ & 0,4576 & 0,0429 & 0,1447 & $\mathbf{0 , 6 3 8 6}$ & 0,3388 \\
México & $\mathbf{0 , 8 0 2 5}$ & 0,3840 & $-0,0262$ & 0,3762 & $\mathbf{0 , 7 2 5 3}$ & 0,3529 \\
Holanda & $\mathbf{0 , 8 0 8 4}$ & $-0,4413$ & $-0,1087$ & $\mathbf{0 , 9 0 7 4}$ & 0,1225 & 0,1471 \\
Cingapura & $\mathbf{0 , 7 6 4 5}$ & 0,0173 & 0,4323 & 0,4738 & 0,2560 & $\mathbf{0 , 6 9 4 0}$ \\
Reino Unido & $\mathbf{0 , 8 3 4 7}$ & $-0,3656$ & $-0,0577$ & $\mathbf{0 , 8 6 9 5}$ & 0,1760 & 0,2158 \\
EUA & $\mathbf{0 , 8 2 4 1}$ & $-0,3122$ & 0,0434 & $\mathbf{0 , 8 0 6 6}$ & 0,1748 & 0,3119 \\
\hline Autovalores & $\mathbf{7 , 9 2 9 0}$ & 1,8803 & 1,1163 & 5,3075 & 3,4351 & 2,1830 \\
\hline Variação (\%) & 49,56 & 11,75 & $\mathbf{6}, 98$ & 33,17 & 21,47 & 13,64 \\
\hline \% acumulado & $\mathbf{0}, 56$ & 61,31 & 68,29 & 33,17 & 54,64 & 68,29 \\
\hline & & & & & \\
\hline
\end{tabular}

Sem priorizarum índice específico em detrimento de outro, aplicou-se, nas presentes simulações, a diversificação dita ingênua, típica do investidor que não tem conhecimento a respeito do mercado acionário. Essa diversificação consiste em aplicar a mesma proporção de recursos em cada índice, ou seja, divide-se o recurso disponível pelo número total de ativos escolhidos.

O retorno estimado de cada carteira é representado pela expressão (2), enquanto que sua variância pela expressão (3). Nas comparações, utilizou-se, para mensurar o risco, o desvio padrão, que é dado pela raiz quadrada da variância.

$$
\begin{aligned}
& \bar{R}=E(I)=\omega_{1} \cdot \bar{I}_{1}+\omega_{2} \cdot \bar{I}_{2}+\cdots+\omega_{n} \cdot \bar{I}_{n} \\
& \sum \omega=1 \\
& \sigma_{R}^{2}=\omega_{1}^{2} \cdot \sigma_{1}^{2}+\omega_{2}^{2} \cdot \sigma_{2}^{2}+\cdots+\omega_{n}^{2} \cdot \sigma_{n}^{2}+ \\
& +2 \cdot\left[\omega_{1} \cdot \omega_{2} \cdot \operatorname{cov}\left(I_{1}, I_{2}\right)+\omega_{1} \cdot \omega_{3} \cdot \operatorname{cov}\left(I_{1}, I_{3}\right)+\right. \\
& \left.+\cdots+\omega_{n-1} \cdot \omega_{n} \cdot \operatorname{cov}\left(I_{n-1}, I_{n}\right)\right]
\end{aligned}
$$

Onde:

$\bar{R}$ ou $E(I)$ é o retorno médio esperado da carteira I; 
$I_{i}$ representa cada um dos índices que compõem a carteira;

$\omega_{i}$ representa a proporção de recursos aplicados no índice $\mathrm{I}_{\mathrm{i}}$;

$n$ é o número total de índices (ou ativos) que compõem a carteira;

$\sigma_{i}^{2}$ é a variância do índice, ou da carteira quando $\mathrm{i}=\mathrm{R}$;

$\operatorname{cov}\left(I_{i} ; I_{n}\right)$ é a covariância entre os índices $\mathrm{I}_{\mathrm{i}}$ e $\mathrm{I}_{\mathrm{n}}$.

Para a formação da carteira 1, foram utilizados os índices das 16 bolsas estudadas.

A carteira 2, composta por França, Egito, Cingapura e Israel, foi formada pelo índice com maior retorno em cada bloco, priorizando-se o maior ganho possível, sem haver preocupação com o risco.

A carteira 3, composta por Cingapura, Israel, Estados Unidos e Indonésia, busca o índice com menor risco em cada um dos blocos, priorizandose alguma segurança

A carteira 4 contou com o índice de maior retorno e o de menor risco de cada bloco. Neste caso, permanece Israel, por ser único em seu grupo, e Cingapura, por ter maior retorno e menor risco em seu grupo. Os demais componentes são França, Egito, Estados Unidos e Indonésia.

Os indicadores calculados para cada uma das quatro carteiras simuladas são ilustrados na Tabela 4. Pode-se observar que a carteira 2 foi a que apresentou o maior retorno e o maior risco, enquanto que a carteira 3 apresentou o menor risco, mas também o menor retorno. Analisando o coeficiente de variação - que é uma medida de variação relativa, dada pela razão entre o desvio padrão e a média - verifica-se que as carteiras 2 e 4 apresentam semelhança, denotando que são as opções menos arriscadas. Em outras palavras, o maior risco absoluto seria compensado pelo retorno mais elevado.

TABELA 4 - Indicadores das carteiras simuladas

\begin{tabular}{lcccc}
\hline Carteira & $\mathbf{1}$ & $\mathbf{2}$ & $\mathbf{3}$ & $\mathbf{4}$ \\
\hline Proporção de recursos por índice & $6,25 \%$ & $25 \%$ & $25 \%$ & $16,67 \%$ \\
Retorno Médio (a. m.) & $1,41 \%$ & $2,22 \%$ & $1,20 \%$ & $1,84 \%$ \\
Risco (a. m.) & $5,57 \%$ & $7,91 \%$ & $5,25 \%$ & $6,46 \%$ \\
Coeficiente de Variação & $395 \%$ & $356 \%$ & $440 \%$ & $351 \%$ \\
\hline
\end{tabular}

A comprovação da eficácia da métrica proposta pode ser observada se forem obtidos ativos cujos índices apresentem alguma correlação negativa entre si, fato que não ocorreu com os dados disponíveis para o estudo. Entretanto, ao analisar a variação relativa na Tabela 4 , observase que a diversificação absoluta (usando todos os índices) não se mostrou mais apropriada, ou seja, o equilíbrio deve ser considerado. Soma-se a isso o fato de que, nesse caso, não foram levados em conta os custos de transação - que podem aumentar à medida que se aplicam recursos em um local adicional.
$\mathrm{Na}$ seção seguinte são apresentadas considerações gerais acerca do desenvolvimento deste estudo, bem como recomendações para estudos futuros nesta mesma área.

\section{CONSIDERAÇÕES FINAIS E RECOMENDA̧ÇÕES}

O presente trabalho teve como objetivo avaliar o grau de integração em um conjunto de macrocarteiras de investimentos financeiros valendose dos índices das Bolsas de Valores dos mercados 
acionários localizados nos seguintes países: Índia, Brasil, Egito, França, Alemanha, Hong Kong, Indonésia, Israel, Japão, Malásia, Argentina, México, Holanda, Cingapura, Reino Unido e Estados Unidos.

O estudo compreendeu o período de janeiro de 1998 a dezembro de 2006, pautando-se nas taxas de rentabilidade discretas dos respectivos índices do mercado acionário das 16 economias supracitadas.

O método usado para alcançar os objetivos pretendidos foi a Análise Fatorial, que permitiu observar a formação de agrupamentos (blocos) ou macrocarteiras de investimentos, após a aplicação da rotação Varimax, a saber: carteira 1: Indonésia, México, Argentina, Índia, Brasil, Japão e Egito; carteira 2: Hong Kong, Estados Unidos, Reino Unido, Alemanha, Holanda e França; carteira 3: Malásia e Cingapura; e carteira 4: Israel. Notadamente, apenas a Bolsa de Valores situada em Israel não apresentou relacionamento com as dos demais países.

Apesar da grande volatilidade, representando os riscos dos retornos desses índices de ações, esses mercados ainda continuam sendo bastante atrativos para o investidor internacional. Este investidor, porém, não investe nos mercados emergentes sem diversificar as suas carteiras, aplicando em diferentes mercados.

Percebeu-se ainda que a volatilidade nos mercados acionários pesquisados tem decrescido à medida que eles estão se tornando mais integrados. Esse fato pode ser atribuído à maior diversificação das informações (domésticas e internacionais) que passaram a influenciar os preços dos ativos financeiros, além do acréscimo do volume negociado diariamente.

Os resultados obtidos para as macrocarteiras mensuradas sob a ótica da moderna teoria de finanças demonstraram a eficácia da métrica da análise fatorial como mais um instrumento para compor carteiras que levem a uma minimização dos riscos.

Ainda assim, o mercado financeiro internacional, a cada dia que passa, vem sofrendo pressões no sentido de que novas regulamentações sejam incorporadas, sob pena de os bancos centrais ficarem reféns dos capitais de curto prazo, sem a eficácia das políticas econômicas adotadas por essas instituições, o que dá sustentação ao sistema financeiro global.

Sugere-se, para o desenvolvimento de estudos futuros, que seja feita a análise do efeito do processo de diversificação valendo-se também de instrumentos de renda fixa, incluindo-se, assim, títulos de diferentes países, em diferentes períodos de maturidade, sem deixar de observar previamente as magnitudes de direções das correlações entre esses ativos financeiros.

\section{REFERÊNCIAS}

BAILEY, W.; STULZ, R. M. Benefits of international diversification: the case of pacific basin stock markets. Journal of Portfolio Management, New York, v. 40, n. 4, p. 57-61, 1990.

BERNSTEIN, P. L. Desafio aos deuses: a fascinante história do risco. 20. ed. Rio de Janeiro: Campus, 1997.

BODIE, Z.; KANE, A.; MARCUS, A. J. Fundamentos de investimentos. 3. ed. Porto Alegre: Bookman, 2000.

BRACKER, K.; DOCKING, D. S.; KOCH, P. D. Economic determinants of evolution in international stock marketintegration. Journal of Empirical Finance, New York, v. 6, p. 1-27, 1999.

CARVALHO, M. A.; SILVA, C. R. L. Economia internacional. 2. ed. São Paulo: Saraiva, 2000.

DAMODARAN, A.; BERNSTEIN, P. L. Administração de investimentos. 2. ed. Porto Alegre: Bookman, 2000.

GONÇALVES, R. Globalização financeira, liberalização cambial e vulnerabilidade externa da economia brasileira. In: BAUMANN, R. (Org.). O Brasil e a economia global. São Paulo: Campus, 1996.

HAIR Jr., J. F. et al. Análise multivariada de dados. 5. ed. Porto Alegre: Bookman, 2005.

INTERNATIONAL FINANCE CORPORATION IFC. Disponível em: < http:/ / www.ifc.org > . Acesso em: 27 dez. 2006.

JUNG, C. F. Metodologia para pesquisa e desenvolvimento: aplicada a novas tecnologias, produtos e processos. Rio de Janeiro: Axcel Books, 2004.

KOEN, V.Economista chefe da OCDE. Entrevista concedida à $\mathrm{BBC}$ em 9 de setembro de 2002. Disponível em: $<$ http://www.bbc.co.uk/portuguese/economia/020908_ economiadb.shtml>. Acesso em: 26 dez. 2006.

KRUGMAN, P.; OBSTFELD, M. Economia internacional: teoria e política. 4. ed. São Paulo: Makron Books, 1999. 
LESSARD, D. R. International portfolio diversification: a multivariate analysis for a group of Latin American countries. Journal of Finance, New York, v. 28, p. 619-633, 1973.

MARKOWITZ, H. Portfolio selection. Journal of Finance, v. 7,n.1,p. 77-91,1952.Disponível em: $<$ http:/ / cowles.econ.yale.edu/P/cp/p00b/p0060.pdf >. Acesso em: 24 jun. 2006.

MISHKIN, F. S. Moedas, bancos e mercados financeiros. 5. ed. Rio de Janeiro: LTC, 2000.

MULLIN, J. Emerging equity markets in the global economy. Federal Reserve of New York Quarterly Review, New York, Summer, p. 54-83, 1993.

YAHOO FINANCE. Maiores índices mundiais. Disponível em: < http://br.finance.yahoo.com/intelindices>. Acesso em: 20 dez. 2006.

Recebido: 15/06/2009

Received: 06/15/2009

Aprovado: $12 / 08 / 2009$

Approved: 08/12/2009 